\title{
A Comparative Study of Metal Readsorption in the Application of a Three-Stage Sequential Extraction Scheme and Two Accelerated Versions (Ultrasonic and Single Extractions)
}

\author{
G. Pérez ${ }^{\mathrm{a}}, \mathrm{M}$. Valiente ${ }^{\mathrm{a}}$ and C. Bendicho ${ }^{*}, \mathrm{~b}$ \\ ${ }^{a}$ Universitat Autònoma de Barcelona, Centre Grup de Tècniques de Separació, Unitat de Química Analítica, Depar- \\ tament de Quimica, 08193, Bellaterra, Barcelona, Spain \\ ${ }^{b}$ Universidade de Vigo, Departamento de Química Analítica y Alimentaria (Area de Química Analítica), Facultad de \\ Ciencias (Química), As Lagoas-Marcosende s/n 36200, Vigo, Spain
}

\begin{abstract}
Accelerated methods for partitioning of $\mathrm{Cd}, \mathrm{Cr}, \mathrm{Cu}, \mathrm{Ni}, \mathrm{Pb}$ and $\mathrm{Zn}$, such as the use of single and ultrasonic extractions are assessed in terms of readsorption and compared with the three-stage sequential extraction scheme (SES) of the Standards Measurements and Testing Programme (SM\&T). The standard addition approach was employed for characterising the readsorption artefact by applying the above fractionation methods over different certified reference materials (CRMs), BCR 701, BCR 601 (lake sediments), and BCR 141R soil. Ultrasonic extractions provided higher readsorption, mainly for BCR $141 \mathrm{R}$ and 601 as compared to conventional SES, the role of ultrasound in the activation of adsorptive sites being significant. The single extraction approach seemed to be inadequate with samples containing large amounts of carbonates such as BCR $141 \mathrm{R}$ but worked well with both lake sediments.

The readsorption phenomena are mainly occurring in the most labile fraction (i.e. acid soluble) and has been observed to be matrix dependent. The extent of such phenomenon is also dependent on the extraction methodology, i.e conventional $v s$ accelerated.
\end{abstract}

\section{INTRODUCTION}

Since Tessier's contribution [1] and the Community Bureau of Reference (BCR) harmonization [2], sequential extraction schemes (SESs) have been widely applied and, thus, received an increasing attention during last years to estimate metal mobility and availability in the environment [3]. Several methods for speeding up metal fractionation in order to overcome the time-consuming drawback of SESs, such as application of single extractions or microwave and ultrasonic treatments, have been developed. Single extractions [4] as a simple modification of SESs, i.e. just performing simultaneously the extractions over different aliquots of the same sample, allow diminishing the whole treatment up to a day. The fraction contents, except the first one, are evaluated by subtracting the results obtained in two consecutive stages. On the other hand, ultrasonic versions of SESs have demonstrated their potential for drastic acceleration of conventional SESs, providing similar extractability for several metals in a variety of environmental samples [5-9]. Microwave treatments may be less suitable for shortening the operation time in SESs since the heating could cause significant changes on metal extraction and fractionation, being the labile fractions the most affected [10-13].

The readsorption artefact has been identified as one of the most significant problems affecting the results obtained

*Address correspondence to this author at the Universidade de Vigo, Departamento de Química Analítica y Alimentaria (Area de Química Analítica), Facultad de Ciencias (Química), As Lagoas-Marcosende s/n 36200, Vigo, Spain; Tel: +34-986-812281; Fax: +34-986-812556;

E-mail: bendicho@uvigo.es by sequential extractions [14] As a result of readsorption, the concentration of trace metals associated with the dissolving phase is underestimated whereas the concentration of trace metals associated with the receiving phase is overestimated. Three different approaches have been employed to assess the extent of readsorption, i.e. use of model synthetic phases, natural sediments spiked with model synthetic phases and the standard addition method. Kheboian and Bauer [15], using model synthetic phases, observed a significant readsorption of $\mathrm{Cu}, \mathrm{Pb}$ and $\mathrm{Zn}$ when the Tessier scheme was applied. Ajayi and Vanloon [16] employed the natural sediments spiked with model synthetic phases with the aim of supplying fresh unoccupied sites for retention of any metals released during extraction. The main readsorption was attributed to $\mathrm{Cr}, \mathrm{Pb}$ and $\mathrm{Zn}$ over iron and manganese oxides and organic matter. However, using a slightly modified second approach over the BCR-SES, Whalley et al. [17] observed that certain model phases e.g. humic acids and ferrihydrite generally released trace metals earlier than expected. Thus, both approaches, employing artificial model phases, differ markedly from natural sediments, thus biasing the system towards trace metal redistribution.

The observed drawbacks in the readsorption assessment by the commented approaches are overcome by the standard addition method. This would be an appropriate approach provided that the spiked metal concentrations were below $100 \%$ of the natural existing concentrations in the studied samples; otherwise the readsorption problem would be confused with a probably biasing of the system towards metal redistribution [18]. Anyway, the standard addition should not exceed the native concentration in the sample so that the 
existing equilibrium is not significantly perturbed by the alteration of the extraction conditions.

To our knowledge, accelerated fractionation methods applied to obtain fast information about extractable metal contents have not been characterised in respect to readsorption in the SM\&T-SES (Standard Measurements and Testing Program, formerly BCR-SES). Therefore, the aim of this work is to study the extent of the readsorption artefact when using, on one hand, ultrasonic extractions, and on the other hand, single extraction methodology to a conclusive comparison with the conventional SM\&T-SES.

\section{EXPERIMENTAL}

\section{Apparatus and Reagents}

$\mathrm{Cd}, \mathrm{Cr}, \mathrm{Cu}, \mathrm{Ni}, \mathrm{Pb}$ and $\mathrm{Zn}$ were determined in both, extracts and aqua regia digests, using a Perkin Elmer inductively coupled plasma optical emission spectrometer (ICPOES-axial view) (model Optima 4300 DV, Norwalk, CT, USA). Matrix-matched standards with extractants were used for calibration. Calibration standards and reagent blanks were frequently reanalysed as samples for quality control purposes. Analytical grade reagents (Panreac and Merck) were used throughout. All extractant, standards, and rinse solutions were made from ultrapure water with a resistivity greater than $18 \mathrm{M} \Omega \cdot \mathrm{cm}$, using a Milli-Q water purification system (Millipore, Molsheim, France). All glassware and plastic containers were previously soaked overnight in $25 \%$ nitric acid and rinsed. Sample digestions for pseudototal determination were performed in perfluoroalcoxy (PFA) vessels, with a CEM Corporation microwave laboratory unit (CEM Mars X, Mathews, NC, USA). Ultrasonic agitation was performed using a $100 \mathrm{~W}, 20 \mathrm{KHz}$ probe sonicator (Sonics and Materials; model VC 100), equipped with titanium probes. Extracts were separated from solid residues using an Alresa centrifuge (model C-5, Barcelona, Spain). A Crison $\mathrm{pH}$-meter (model 2001 micropH) was used for $\mathrm{pH}$ adjustments of the extracts.

\section{Certified Reference Materials}

Three certified reference materials (CRMs) were employed in this study for assessing readsorption, a description of their main characteristics being shown in Table 1. Among the considered CRMs, BCR 701 and 601 are both lake sediments, while BCR $141 \mathrm{R}$ is a heavy metal contaminated soil. BCR 701, 601 and 141R were obtained from the SM\&T of the European Commission. BCRs 701 and 601 are provided with certified/indicative fraction-specific metal concentrations according to the modification of the BCR-SES that lead to the SM\&T-SES [19]. No sequential extraction data is available for BCR $141 \mathrm{R}$, which provides only aqua regia soluble contents. Major compositions and total extractable metal contents of the CRMs studied are shown in Table $\mathbf{1}$.

\section{Analytical Procedures}

Extraction conditions corresponding to each stage of the employed SM\&T-SES are shown in Table 2. An ultrasonic version of this SES was applied following previously optimised conditions for treatments with an ultrasonic probe [6]. To properly compare individual results of each fraction, ultrasound extractions were always applied over the remaining residues after removal of the previous fractions using the conventional SES. The single extraction approach followed the same operational conditions than the conventional procedure shown on the left of the table, but over fresh samples in every step. Accelerated and conventional extractions were performed by triplicate, including samples, vessel, reagent and procedural blanks, which were run simultaneously. As a quality control, a mass balance was established by comparing the pseudototal metal content (i.e. applying a microwave digestion with $\mathrm{HCl}+\mathrm{HNO}_{3}$ ) with the sum of the extracted metal percentages in the four steps. After each step of SES, the suspension was centrifuged and the supernatant from the solid phase separated. Extracts were filtered through 0.22micron filter Millex-GS (Millipore, Ireland) in order to avoid the clogging of the nebulizer when using ICP-OES. The resulting extracts were stored in polypropylene bottles refrigerated at $4^{\circ} \mathrm{C}$ prior to analysis, with the exception of the extracts corresponding to the second fraction, which were analysed immediately due to the instability and degradation of the extractant reagent.

In order to compare the relative extractability of the fractionation approaches tried, the term 'recovery' was employed as in earlier studies $[6,13]$, which is defined as follows:

Table 1. Description of the CRMs Examined in this Study. Major Composition and Total Trace Metals of the CRMs Studied

\begin{tabular}{|c|c|c|c|c|c|c|c|c|c|c|c|c|c|c|}
\hline \multirow{2}{*}{ CRM } & \multicolumn{8}{|c|}{ Major Components (\%) } & \multicolumn{6}{|c|}{ Total metal $\left(\mathrm{mg} \cdot \mathrm{kg}^{-1}\right)$} \\
\hline & $\mathrm{SiO}_{2}$ & $\mathbf{A l}_{2} \mathbf{O}_{3}$ & MgO & $\mathrm{TiO}_{2}$ & $\mathrm{Fe}_{2} \mathrm{O}_{3}$ & $\mathbf{P}_{2} \mathbf{O}_{5}$ & $\mathbf{K}_{2} \mathbf{O}$ & $\begin{array}{c}\text { Organic C } \\
\text { (wt.\%) }\end{array}$ & Cd & $\mathrm{Cr}$ & $\mathrm{Cu}$ & $\mathbf{N i}$ & $\mathbf{P b}$ & $\mathbf{Z n}$ \\
\hline $\begin{array}{l}\text { BCR 141R [20] } \\
\text { Calcareous loam soil from upper } 10 \mathrm{~cm} \\
\text { of fields near Pellegrino, Italy. Ground } \\
\text { to }<90 \mu \mathrm{m} \text {. }\end{array}$ & 51.1 & 11.6 & 2.3 & 0.6 & 4.0 & 0.4 & 1.6 & 11 & 14.6 & 195 & 46.4 & 103 & 57.2 & 283 \\
\hline $\begin{array}{l}\text { BCR } 701[21] \\
\text { Lake sediment from different sampling } \\
\text { sites of Lake Orta, Italy known for } \\
\text { serious metal contamination. Ground to } \\
<90 \mu \mathrm{m}\end{array}$ & 59.4 & 15.6 & 3.2 & 0.7 & 6.4 & 0.5 & 2.6 & 10 & 11.7 & 272 & 275 & 103 & 143 & 454 \\
\hline $\begin{array}{l}\text { BCR } 601[22] \\
\text { Lake sediment from different sampling } \\
\text { sites of Lake Flumendosa, Italy. Col- } \\
\text { lected in March } 1994 \text {. } \\
\text { Ground to }<90 \mu \mathrm{m} \text {. }\end{array}$ & 48.8 & 13.9 & 2.2 & 0.8 & 7.3 & 0.9 & 2.6 & 5 & 11 & 148 & 240 & 72 & 231 & 824 \\
\hline
\end{tabular}


Table 2. Analytical Conditions and Chemical Reagents for the Conventional SES and Ultrasonic Extractions, Both with the aqua regia Digestion Add-On Step. The Single Extraction Approach Follows the Same Operational Conditions than the Conventional SES But Over Fresh Samples in Every Step. Moisture Content of CRMs was Determined by Drying it at $105^{\circ} \mathrm{C}$ Until Constant Weight.

\begin{tabular}{|c|c|c|c|}
\hline \multirow{2}{*}{ Step } & \multirow{2}{*}{ Fraction } & \multicolumn{2}{|c|}{ Chemical Reagents and Conditions } \\
\hline & & Conventional Extraction SM\&T-SES & Ultrasonic Extraction \\
\hline 1 & $\begin{array}{l}\text { Acid soluble } \\
\quad(\mathrm{F} 1)\end{array}$ & $\begin{array}{l}0.5 \mathrm{~g} \text { of CRM portion, } 20 \mathrm{ml} 0.11 \mathrm{M} \text { acetic acid, shake } 16 \mathrm{~h} \text {. } \\
\text { Centrifugation and separate extract from residue at } 3000 \mathrm{~g} \text { for } \\
20 \mathrm{~min} \text {. }\end{array}$ & $\begin{array}{l}0.5 \mathrm{~g} \text { of CRM portion, } 20 \mathrm{ml} 0.11 \mathrm{M} \text { acetic acid, } 12 \mathrm{~min} \text { ultra- } \\
\text { sonic sonication at } 50 \% \text { amplitude. Centrifugation and separate } \\
\text { extract from residue at } 3000 \mathrm{~g} \text { for } 20 \mathrm{~min} \text {. }\end{array}$ \\
\hline 2 & Reducible (F2) & $\begin{array}{l}\text { Add } 20 \mathrm{ml} 0.5 \mathrm{M} \mathrm{NH}_{2} \mathrm{OH} \cdot \mathrm{HCl}(\mathrm{pH} \approx 1.5) \text { to step } 1 \text { residue, } \\
\text { shake } 16 \mathrm{~h} \text {. Centrifugation as in step } 1 .\end{array}$ & $\begin{array}{l}\text { Add } 20 \mathrm{ml} 0.5 \mathrm{M} \mathrm{NH}_{2} \mathrm{OH} \cdot \mathrm{HCl}(\mathrm{pH} \approx 1.5) \text { to step } 1 \text { residue, ultra- } \\
\text { sonic sonication during } 9 \text { min at } 50 \% \text { amplitude. Centrifugation } \\
\text { as in step } 1 \text {. }\end{array}$ \\
\hline 3 & Oxidisable (F3) & $\begin{array}{l}\text { Add } 5 \mathrm{ml} \mathrm{H}_{2} \mathrm{O}_{2} \mathrm{pH}(2-3) \text { to sep } 2 \text { residue digesting at room } \\
\text { temperature during } 1 \mathrm{~h} \text {, heat to } 85 \pm 2^{\circ} \mathrm{C} \text { for } 1 \mathrm{~h} \text {, add further } 5 \\
\mathrm{ml}_{2} \mathrm{O}_{2} \text { and heat to } 85 \pm 2^{\circ} \mathrm{C} \text { for } 1 \mathrm{~h} \text {; add } 25 \mathrm{ml} 1 \mathrm{M} \\
\mathrm{NH}_{4} \mathrm{OAc}(\mathrm{pH} \text { 2) and shake } 16 \mathrm{~h} \text {. Centrifugation as in step } 1 \text {. }\end{array}$ & $\begin{array}{l}\text { Add } 5 \mathrm{ml} \mathrm{H}_{2} \mathrm{O}_{2} \mathrm{pH}(2-3) \text { to sep } 2 \text { residue digesting at room tem- } \\
\text { perature during } 1 \text { h. Digest with ultrasound during } 9 \text { min at } 50 \% \\
\text { amplitude, heat near dryness and add } 25 \mathrm{ml} 1 \mathrm{M} \mathrm{NH}_{4} \mathrm{OAc}(\mathrm{pH} 2) \text {, } \\
\text { ultrasonic sonication } 6 \text { min at } 50 \% \text { amplitude. Centrifugation as } \\
\text { in step } 1 \text {. }\end{array}$ \\
\hline 4 & Residual (F4) & \multicolumn{2}{|c|}{$\begin{array}{l}\text { Validated microwave-assisted digestion of step } 3 \text { residue with } 6 \mathrm{ml} \mathrm{HCl} \text { conc, } 2 \mathrm{ml} \mathrm{HNO}{ }_{3} \text { conc }, 1 \mathrm{ml} \mathrm{H}_{2} \mathrm{O} \text {. Also used for pseudototal } \\
\text { digestion of } 0.25 \mathrm{~g} \text { of original CRM using the same acid mixture. }\end{array}$} \\
\hline
\end{tabular}

Recovery $(\%)=[$ Metal released by ultrasonic or single extractions] / [Metal released by the conventional three-stage $\mathrm{SES}] \times 100$

\section{Standard Addition Experiments}

Experiments were addressed to estimate the extent of the readsorption phenomena of each metal $(\mathrm{Cd}, \mathrm{Cr}, \mathrm{Cu}, \mathrm{Ni}, \mathrm{Pb}$ and $\mathrm{Zn}$ ) in every fraction of the SM\&T-SES. Firstly, the conventional procedure was carried out in order to determine the appropriate metal amounts to be spiked in a particular fraction. Then, a new SES was performed on a separate sample portion after appropriate addition of small volumes (50$300 \mu \mathrm{l})$ of acidified metal stock solutions. Thus, for F1 readsorption estimation, the spike was added to a fresh sample portion. For F2 and F3, the corresponding spikes were added to the remaining portions generated after F1 and F2 of the conventional SES, respectively. The spikes contained no more than $100 \%$ of the "native" extracted amount by the conventional SES, in order to maintain the normal extraction conditions.

In order to check for possible bias that could affect the assessment of readsorption, other different source of metal losses than that corresponding to the readsorption artefact were investigated. The blank experiments using the same volume of spiked extractant reagent showed that no losses by adsorption onto the wall of the treatment vessels were present during the sequential extraction experiments. On the other hand, non-significant metal amounts were detected in the rinsing water. Readsorption values (\%) were obtained considering the difference between the measured concentrations $(\mu \mathrm{g} / \mathrm{mL})$ of the metal in the extracts corresponding to treatments with non-spiked $[\mathrm{M}]_{\mathrm{A}}$ and spiked $[\mathrm{M}]_{\mathrm{C}}$ extractant. This difference was compared with $[\mathrm{M}]_{\mathrm{B}}$, which is the concentration $(\mu \mathrm{g} / \mathrm{mL})$ of the element added to the extractant before the treatment. The readsorption (\%) is calculated as follows:

\section{Readsorption (\%) $=\left\{1-\left([\mathrm{M}]_{\mathrm{C}}-[\mathrm{M}]_{\mathrm{A}}\right) /[\mathrm{M}]_{\mathrm{B}}\right\} \times 100$ RESULTS AND DISCUSSION}

\section{Fractionation Patterns}

Ultrasonic extractions, single extractions and conventional SES are compared. Firstly, CRM BCR 601 and CRM BCR 701 were employed for validation of SM\&T-SES. In all cases, a good agreement between certified/indicative and found extractable contents is observed (Table 3 ).

It would be expected that in terms of recovery, single extractions did not significantly change the fractionation patterns of the considered metals and gave a similar performance, since the first fraction is common to the conventional procedure and operational conditions (e.g. extractant concentration, agitation time, temperature, etc) remain unchanged. However, while no significant differences between single and conventional extraction for all the metals in the sediment CRMs are observed when the F2 content is estimated, single extractions provide an efficient extraction only for $\mathrm{Cd}$ when applied to the soil CRM. The high lability of this element and its main association with manganese oxides would explain $\mathrm{Cd}$ behaviour. For the rest of elements, matrix characteristics would account for the lack of extractability in the single extraction. The high carbonate content of BCR $141 \mathrm{R}$, would probably consume an important part of the extractant reagent, being not enough the $\mathrm{H}^{+}$available for completely dissolve the different components that typically are related to reducible fraction (manganese oxides, crystalline and amorphous iron oxyhidroxydes).

With a few exceptions (e.g. Pb in BCR 601), single extraction yielded good recoveries in the oxidable fraction. When total extractable contents are compared (sum of $\mathrm{F} 1+\mathrm{F} 2+\mathrm{F} 3$ ) (Table 4), single extractions yielded recoveries in the range $90-110 \%$ for all metals in both sediments. However, as expected, low recoveries for total extractable content $(<60 \%)$ are achieved with the soil sample except for $\mathrm{Cd}$. 
Table 3. Indicative and Experimental Extractable Concentrations for $\mathrm{Cd}, \mathrm{Cr}, \mathrm{Cu}, \mathrm{Ni}$, $\mathrm{Pb}$ and $\mathrm{Zn}$ in $\mathrm{BCR} 601$ and $701 \mathrm{CRMs}$ $(\mathrm{mg} / \mathrm{kg})$ Using the Conventional Extraction Procedure

\begin{tabular}{|c|c|c|c|c|c|c|c|c|c|c|}
\hline & \multicolumn{4}{|c|}{ Cd } & \multicolumn{3}{c|}{ Cr } & \multicolumn{2}{c|}{ Cu } \\
\cline { 3 - 11 } & & F1 & F2 & F3 & F1 & F2 & F3 & F1 & F2 & F3 \\
\hline \hline \multirow{2}{*}{ BCR 701 } & Found & $7.0 \pm 1.5$ & $3.1 \pm 0.3$ & $0.24 \pm 0.05$ & $2.5 \pm 0.5$ & $45.8 \pm 0.8$ & $142 \pm 8$ & $49 \pm 4$ & $116 \pm 5$ & $55 \pm 10$ \\
\cline { 2 - 12 } & Certified & $7.34 \pm 0.35$ & $3.77 \pm 0.28$ & $0.27 \pm 0.06$ & $2.26 \pm 0.16$ & $45.7 \pm 2.0$ & $143 \pm 7$ & $49.3 \pm 1.7$ & $124 \pm 3$ & $55.2 \pm 4.0$ \\
\hline \multirow{2}{*}{ BCR 601 } & Found & $4.01 \pm 0.7$ & $4.0 \pm 0.5$ & $1.52 \pm 0.10$ & $0.39 \pm 0.03$ & $10.0 \pm 0.5$ & $13.5 \pm 1.5$ & $9.5 \pm 1.0$ & $71 \pm 2$ & $75 \pm 4$ \\
\cline { 2 - 11 } & Indicative & $4.5 \pm 0.6$ & $3.95 \pm 0.5$ & $1.91 \pm 1.3$ & $0.35 \pm 0.07$ & $10.6 \pm 0.8$ & $14 \pm 2$ & $10.5 \pm 0.7$ & $73 \pm 5$ & $79 \pm 8$ \\
\hline
\end{tabular}

\begin{tabular}{|c|c|c|c|c|c|c|c|c|c|c|}
\hline & \multicolumn{4}{|c|}{ Ni } & \multicolumn{3}{c|}{ Pb } & \multicolumn{2}{c|}{} \\
\cline { 3 - 11 } & & F1 & F2 & F3 & F1 & F2 & F3 & F1 & F2 & F3 \\
\hline \hline \multirow{2}{*}{ BCR 701 } & Found & $16.7 \pm 0.7$ & $27.9 \pm 0.1$ & $15.8 \pm 1.1$ & $3.6 \pm 0.5$ & $119 \pm 4$ & $11 \pm 2$ & $202 \pm 9$ & $112 \pm 3$ & $45 \pm 3$ \\
\cline { 2 - 12 } & Certified & $15.4 \pm 0.9$ & $26.6 \pm 1.3$ & $15.3 \pm 0.9$ & $3.18 \pm 0.21$ & $126 \pm 3$ & $9.3 \pm 2.0$ & $205 \pm 6$ & $114 \pm 5$ & $45.7 \pm 4.0$ \\
\hline \multirow{2}{*}{ BCR 601 } & Found & $8.3 \pm 0.5$ & $10.8 \pm 1.2$ & $6.1 \pm 0.7$ & $2.3 \pm 0.6$ & $210 \pm 4$ & $17.3 \pm 1.3$ & $251 \pm 4$ & $265 \pm 3$ & $107 \pm 7$ \\
\cline { 2 - 12 } & Indicative & $7.8 \pm 0.8$ & $10.6 \pm 1.1$ & $6.0 \pm 1.2$ & $2.3 \pm 0.4$ & $205 \pm 10$ & $20 \pm 5$ & $261 \pm 12$ & $266 \pm 16$ & $106 \pm 10$ \\
\hline
\end{tabular}

Ultrasonic treatment caused higher metal amounts of $\mathrm{Cr}$, $\mathrm{Cu}$ and $\mathrm{Zn}(\mathrm{BCR} 141 \mathrm{R})$ and $\mathrm{Cr}$ and $\mathrm{Pb}(\mathrm{BCR}$ 601) to be released in F1. Such release enhancement by ultrasonic cavitation is also observed for Fe $\left(137 \mathrm{mg} \cdot \mathrm{kg}^{-1}\right.$ against $45 \mathrm{mg} \cdot \mathrm{kg}^{-1}$ in conventional treatment for BCR 141R) and Mn as a consequence of the related oxides disaggregation and colloid formation (smaller than $0.22 \mu \mathrm{m}$ ) Thus, the observed increase of metal release can be attributed to the enhancement of the contact interface between metal oxides and extractant. A comparison of F1 in the three CRMs assayed reveals that
BCR 701 provided the best results as all metals are efficiently recovered, while for the other two CRMs only two metals are similarly extracted (Cd and Ni in BCR 141R; Cd and $\mathrm{Cu}$ in BCR 601). In F2, a general underestimation is observed for Ni due to a clear lack of extraction efficiency by the ultrasonic agitation, also observed in the sediment sample for $\mathrm{Cr}$, another typical residual element. The rest of elements present recoveries around $100 \%$. This is an apparent contradiction because of the relatively different concentrations of the metals released on F1 and F2. In this sense,

Table 4. Summary of Total Extractable Content $(\mathrm{F} 1+\mathrm{F} 2+\mathrm{F} 3)\left(\mathrm{mg} \cdot \mathrm{kg}^{-1}\right)$ Obtained for BCR $141 \mathrm{R}$, BCR 701 and BCR $601 \mathrm{by} \mathrm{Con-}$ ventional SES, Single Extraction and Ultrasonic Extraction

\begin{tabular}{|c|c|c|c|c|c|c|c|}
\hline \multicolumn{2}{|c|}{ CRM/Procedure } & Cd & $\mathrm{Cr}$ & $\mathbf{C u}$ & $\mathbf{N i}$ & $\mathbf{P b}$ & $\mathbf{Z n}$ \\
\hline \multirow{5}{*}{ 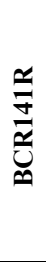 } & Conventional & $10.9 \pm 1.2$ & $49 \pm 2$ & $16.1 \pm 1.3$ & $59 \pm 5$ & $37 \pm 2$ & $144 \pm 17$ \\
\hline & Single Extraction & $11.9 \pm 0.5$ & $30.9 \pm 0.8$ & $9.5 \pm 0.7$ & $24 \pm 3$ & $8 \pm 3$ & $87 \pm 5$ \\
\hline & Recovery $(\%)^{\mathrm{a}}$ & 110 & 63 & 59 & 41 & 21 & 60 \\
\hline & Ultrasound & $9.4 \pm 0.3$ & $46.9 \pm 1.0$ & $25.2 \pm 1.7$ & $17.0 \pm 1.0$ & $40.4 \pm 0.8$ & $146 \pm 5$ \\
\hline & Recovery $(\%)^{\mathrm{a}}$ & 86 & 95 & 157 & 29 & 109 & 101 \\
\hline \multirow{5}{*}{ 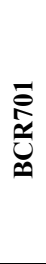 } & Conventional & $10.4 \pm 1.5$ & $191 \pm 8$ & $220 \pm 12$ & $59.9 \pm 1.3$ & $132 \pm 5$ & $360 \pm 10$ \\
\hline & Single Extraction & $10.8 \pm 0.5$ & $187 \pm 10$ & $213 \pm 8$ & $56.1 \pm 0.9$ & $138 \pm 5$ & $363 \pm 14$ \\
\hline & Recovery $(\%)^{\mathrm{a}}$ & 105 & 96 & 97 & 94 & 105 & 101 \\
\hline & Ultrasound & $11.3 \pm 0.8$ & $159 \pm 5$ & $209 \pm 7$ & $48.5 \pm 1.5$ & $126 \pm 4$ & $322 \pm 2$ \\
\hline & Recovery $(\%)^{a}$ & 109 & 83 & 95 & 81 & 95 & 90 \\
\hline \multirow{5}{*}{$\begin{array}{l}\bar{\delta} \\
\stackrel{0}{0} \\
\text { 0. }\end{array}$} & Conventional & $9.4 \pm 0.3$ & $23.8 \pm 0.5$ & $152 \pm 3$ & $26.4 \pm 0.6$ & $229 \pm 16$ & $600 \pm 14$ \\
\hline & Single Extraction & $9.0 \pm 0.9$ & $27.8 \pm 1.4$ & $162 \pm 6$ & $29 \pm 2$ & $218 \pm 6$ & $614 \pm 10$ \\
\hline & Recovery $(\%)^{\mathrm{a}}$ & 96 & 108 & 106 & 112 & 95 & 102 \\
\hline & Ultrasound & $9.3 \pm 0.7$ & $19.1 \pm 0.6$ & $160 \pm 7$ & $15.0 \pm 0.3$ & $199.7 \pm 1.3$ & $445 \pm 4$ \\
\hline & Recovery $(\%)^{\mathrm{a}}$ & 99 & 80 & 105 & 57 & 87 & 74 \\
\hline
\end{tabular}

${ }^{a}$ Recovery is calculated using the ratio: [total metal content $(\mathrm{F} 1+\mathrm{F} 2+\mathrm{F} 3)$ extracted using the accelerated (single extractions or ultrasonic agitation) procedure/total metal content extracted by the conventional sequential procedure] $\times 100$. 
the lower concentrations of F1 can be highly modified by a slight attack of Fe-Mn oxides. This attack does not modify in a noticeable manner the amounts released on F2. In the oxidable fraction most metal recoveries vary in the range (70-130\%). Again, Ni displays lower recovery than that of the conventional procedure. This behaviour is displayed regardless the solid matrix, a fact that is in agreement with previously reported data for $\mathrm{Ni}$ using small-scale studies over BCR 601 [23]. Sonication conditions different than the optimised should be used in order to efficiently recover this element, but would involve an overestimation of the other elements [24]. Finally, total extractable content (sum of $\mathrm{F} 1+\mathrm{F} 2+\mathrm{F} 3$ contents) (Table 4) with ultrasonic agitation were similar in comparison with the conventional protocol except for $\mathrm{Ni}$ (BCR 141R and BCR 601) and Cu (BCR 141R).

\section{Readsorption Studies}

Added amounts and metal readsorptions (\%) for each metal in each CRM for the acid-soluble, reducible and oxidable fraction are shown in Table 5. Repeatability of readsoption values, expressed as relative standard deviation, was better than $9 \%$, with exception of $\mathrm{Pb}$ in the $\mathrm{F} 1$ on BCR $141 \mathrm{R}$ where released amounts were close to the LOD, hence limiting the readsoption quantification.

\section{Conventional Three-Stage SES}

On applying the conventional SM\&T-SES, readsorption occurs for almost all metals and CRMs in F1. Readsorption is especially highlighted ( $>90 \%$ ) in $\mathrm{F} 1$ for $\mathrm{Cu}$ (BCR 141R) and $\mathrm{Pb}$ (BCR 601). Readsorption values in the range $60-90 \%$ are observed for $[\mathrm{Cr}(\mathrm{F} 1), \mathrm{Cd}(\mathrm{F} 3)]$ in $\mathrm{BCR} 701$ and $[\mathrm{Cu}(\mathrm{F} 1)$, $\mathrm{Cu}(\mathrm{F} 3)]$ in BCR 601 (Table 5).

Depending on the matrix characteristics and its buffering capacity, a $\mathrm{pH}$ increment about $2 \mathrm{pH}$ units is observed in $\mathrm{F} 1$ (final $\mathrm{pH}$ of 4.8-5). Comparing with the observed increment in the other fractions (only about $0.5 \mathrm{pH}$ units), this aspect would explain the favoured phenomena of readsorption over remaining active surface sites in the iron and manganese oxides. Some metals (e.g. $\mathrm{Zn}$ ) suffer from readsorption in a similar way than with other SESs, where higher readsorptions are observed when the acid soluble amounts are lower, due to an increase of the number of active sites uncovered in the sample [14]. Another example is the high and wellknown readsorption of $\mathrm{Pb}$ [25], also observed within the studied CRMs. We then consider that readsorbed metal is redistributed to iron and manganese oxides, what has been elsewhere assessed by means of radiochemical techniques [26]. In contrast, the readsorption phenomena was successfully avoided in F2 as a result of the initial acidic conditions and the poor buffering capacity of the matrix, which prevents the $\mathrm{pH}$ to rise, and in turn, readsorption [27]. Within the oxidisable fraction, the soil CRM generally displays a lower readsorption than the sediments. Only $\mathrm{Pb}$ and $\mathrm{Zn}$ present a low and comparable readsorption for the three CRMs. In both sediments, BCR 601 and 701, the readsorption extent is higher for $\mathrm{Cd}, \mathrm{Cr}, \mathrm{Cu}$ and $\mathrm{Ni}$ in comparison with the soil.

\section{Single Extractions}

Readsorption studies are limited to the reducible and oxidable fractions in the single extractions due to similar operational conditions with respect to the conventional procedure in the acid soluble fraction. In this sense, readsorption trends in the first fraction have been already discussed above. For reducible and oxidable fractions, it would be expected that the unattacked fractions during the single extraction procedure would play an important role in the readsorption studies. In general, it can be appreciated from data shown in Table 5, that the previously untreated acid soluble fraction do not markedly affect the readsorption of metals for BCR 601 and 701 in the reducible fraction, being readsorption values similar to those of the conventional SES.

However, in F2, the single extraction approach suffered from high readsorption in BCR 141R for all metals with exception of $\mathrm{Cd}$, which showed no readsorption. The occurrence of significant amounts of carbonates in the soil CRM should account for this behaviour. Thus, carbonate dissolution should consume most of the acid content in the reducing reagent leading to inefficient dissolution of the Fe-Mn oxides, and in turn, to enhanced readsorption.

When comparing the readsorption extent in the single and conventional extraction for the oxidable fraction, almost no differences are observed for all the CRMs (Table 5).

On applying single extractions, high readsorption (i.e. $60-90 \%$ ) was found for $\mathrm{Cr}(\mathrm{F} 2), \mathrm{Cu}(\mathrm{F} 2), \mathrm{Ni}(\mathrm{F} 2)$ on $\mathrm{BCR}$ 141R; $\mathrm{Cr}(\mathrm{F} 1), \mathrm{Cd}(\mathrm{F} 3)$ on BCR 701 and $\mathrm{Cu}(\mathrm{F} 1)$ on BCR 601 or severe readsorption (i.e. $>90 \%$ ) observed for $\mathrm{Cu}(\mathrm{F} 1)$ and $\mathrm{Pb}(\mathrm{F} 2)$ on BCR 141R and $\mathrm{Pb}(\mathrm{F} 1)$ on BCR 601.

In general, a relationship between the readsorption extent and recovery occurs (Table 5). Thus, poor recoveries can be observed for $\mathrm{Cr}(\mathrm{F} 2), \mathrm{Cu}(\mathrm{F} 2)$ and $\mathrm{Ni}(\mathrm{F} 2)$ on $\mathrm{BCR} 141 \mathrm{R}$, which are related with high readsorption.

\section{Ultrasonic Extractions}

As above, a relationship between recovery and the readsorption extent was observed in many cases. High readsorption (i.e. 60-90\%) is observed with $\mathrm{Cd}(\mathrm{F} 3), \mathrm{Pb}(\mathrm{F} 3)$ and $\mathrm{Zn}(\mathrm{F} 3)$ for BCR 141R; $\mathrm{Cr}(\mathrm{F} 1), \mathrm{Cu}(\mathrm{F} 1)$ and $\mathrm{Cd}(\mathrm{F} 3)$ for BCR 701; $\mathrm{Cu}(\mathrm{F} 3)$ for $\mathrm{BCR} 601$. Severe readsorption (i.e. $>90 \%$ ) is observed with $\mathrm{Cr}(\mathrm{F} 1), \mathrm{Cu}(\mathrm{F} 1)$ and $\mathrm{Pb}(\mathrm{F} 1)$ for BCR 601 (Table 5).

In $\mathrm{F} 1$, excess extraction occurs for $\mathrm{Cr}, \mathrm{Cu}$ and $\mathrm{Zn}$ (BCR $141 \mathrm{R})$ by implementing ultrasonic agitation in comparison with the conventional SM\&T SES, which is correlated with lower readsorption (Table 5). On the other hand, for $\mathrm{Cu}$ (BCR 701) and $\mathrm{Ni}$ and $\mathrm{Zn}$ (BCR 601) lower recovery can be observed as a result of enhanced readsorption. Apparently, this relationship is less clear for $\mathrm{Cd}, \mathrm{Cr}$ and $\mathrm{Cu}$ (BCR 601), which display better or the same relative extractability with higher readsorption taking place. In these cases, the role of ultrasound activating the remaining surface would enhance readsorption over freshly new exposed active sites. However, increased extraction efficiency caused by the ultrasonic action should operate on the opposite direction yielding higher metal content in the extract. The rest of metals show similar readsorption percentages as those of the conventional procedure in $\mathrm{F} 1$.

While any CRM generally show a comparable readsorption to the conventional procedure in F2 using ultrasonic agitation, an enhanced readsorption takes place for all metals extracted from BCR $141 \mathrm{R}$ in F3. Higher readsorption is also observed in this fraction for $\mathrm{Cd}, \mathrm{Ni}, \mathrm{Pb}$ and $\mathrm{Zn}$ extracted from BCR 601. Although less easily observed than in the 
Table 5. Added Amounts ( $\mu \mathrm{g})$, Readsorption (RA) and Recovery (RC) Values (\%) for Metals in the Different Fractions of SM\&TSES. Conv (Conventional), US (Ultrasound), Single (Single Extraction)

\begin{tabular}{|c|c|c|c|c|c|c|c|c|c|c|c|c|c|c|}
\hline & \multirow{2}{*}{ CRM } & & \multicolumn{2}{|r|}{ Cd } & \multicolumn{2}{|r|}{$\mathrm{Cr}$} & \multicolumn{2}{|r|}{$\mathrm{Cu}$} & \multicolumn{2}{|r|}{$\mathrm{Ni}$} & \multicolumn{2}{|r|}{$\mathbf{P b}$} & \multicolumn{2}{|r|}{$\mathbf{Z n}$} \\
\hline & & & $(\mu \mathrm{g})$ & RA (RC) & $(\mu \mathrm{g})$ & RA (RC) & $(\mu \mathrm{g})$ & RA (RC) & $(\mu \mathrm{g})$ & RA (RC) & $(\mu \mathrm{g})$ & RA (RC) & $(\mu \mathrm{g})$ & RA (RC) \\
\hline \multirow{9}{*}{ 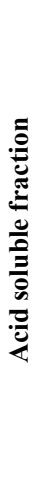 } & \multirow{3}{*}{ BCR 141R } & Conv & \multirow{3}{*}{2.0} & n.s. ${ }^{a}$ & \multirow{3}{*}{0.1} & 27 & \multirow{3}{*}{0.2} & 99 & \multirow{3}{*}{3.0} & 34 & \multirow{3}{*}{ - } & n.d. ${ }^{b}$ & \multirow{3}{*}{3.0} & 58 \\
\hline & & Single & & n.s. & & 27 & & 99 & & 34 & & n.d. & & 58 \\
\hline & & US & & 29 (97) & & n.s. (311) & & $60(405)$ & & $53(82)$ & & n.d. (0) & & 37 (230) \\
\hline & \multirow{3}{*}{ BCR 701} & Conv & \multirow{3}{*}{2.0} & 17 & \multirow{3}{*}{0.6} & 83 & \multirow{3}{*}{13} & 29 & \multirow{3}{*}{4.0} & n.s. & \multirow{3}{*}{0.8} & 54 & \multirow{3}{*}{56} & 11 \\
\hline & & Single & & 17 & & 83 & & 29 & & n.s. & & 54 & & 11 \\
\hline & & US & & $12(109)$ & & $86(107)$ & & 79 (41) & & n.s (110) & & $55(78)$ & & $10(99)$ \\
\hline & \multirow{3}{*}{ BCR 601} & Conv & \multirow{3}{*}{2.0} & n.s. & \multirow{3}{*}{0.5} & 51 & \multirow{3}{*}{5.0} & 82 & \multirow{3}{*}{3.0} & $\mathrm{n} . \mathrm{s}$ & & 94 & & 29 \\
\hline & & Single & & n.s. & & 51 & & 82 & & n.s. & 1.0 & 94 & 120 & 29 \\
\hline & & US & & $41(98)$ & & 95 (266) & & $103(105)$ & & $33(58)$ & & 97 (163) & & $39(74)$ \\
\hline & & Conv & & n.s. & & n.s. & & n.s. & & n.s. & & 34 & & 18 \\
\hline & BCR 141R & Single & 2.5 & n.s. (116) & 12 & $86(10)$ & 4.0 & 89 (23) & 13 & $72(0)$ & 16 & $92(5)$ & 46 & $30(51)$ \\
\hline & & US & & $25(80)$ & & $12(101)$ & & $42(171)$ & & $11(72)$ & & $20(116)$ & & $10(89)$ \\
\hline है & & Conv & & 35 & & n.s. & & 24 & & 12 & & 18 & & 12 \\
\hline$\frac{0}{3}$ & BCR 701 & Single & 1.0 & 15 (116) & 12 & $13(101)$ & 34 & $25(89)$ & 7.0 & n.s. (94) & 34 & 18 (103) & 30 & $12(104)$ \\
\hline$\stackrel{\varrho}{E}$ & & US & & 17 (108) & & $8(68)$ & & $52(105)$ & & n.s. (57) & & $6(97)$ & & $11(63)$ \\
\hline$\approx$ & & Conv & & n.s. & & n.s. & & n.s. & & n.s. & & n.s. & & 10 \\
\hline & BCR 601 & Single & 1.7 & n.s. (82) & 5.0 & n.s (96) & 33 & $18(93)$ & 5.0 & n.s (136) & 92 & n.s $(91)$ & 120 & $19(98)$ \\
\hline & & US & & $50(100)$ & & n.s. (78) & & n.s. (105) & & n.s. (61) & & n.s. (86) & & $13(75)$ \\
\hline & & Conv & & n.s. & & n.s. & & n.s. & & n.s. & & 23 & & 32 \\
\hline & BCR 141R & Single & 0.1 & $39(98)$ & 7.0 & n.s. (110) & 1.6 & n.s (115) & 7.0 & n.s. (76) & 0.5 & 31 (130) & 7.0 & $21(80)$ \\
\hline & & US & & $69(88)$ & & $41(88)$ & & 47 (118) & & $49(41)$ & & $67(72)$ & & $64(88)$ \\
\hline है & & Conv & & 79 & & 55 & & 36 & & 49 & & 20 & & 14 \\
\hline 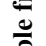 & BCR 701 & Single & 0.5 & 78 (104) & 49 & 59 (97) & 18 & 41 (94) & 5.0 & $45(84)$ & 3.0 & $26(118)$ & 15 & $27(90)$ \\
\hline كَّ. & & US & & $71(138)$ & & $18(91)$ & & $41(104)$ & & n.s. (89) & & $34(71)$ & & n.s. (104) \\
\hline 0 & & Conv & & 32 & & 55 & & 69 & & n.s. & & 17 & & 31 \\
\hline & BCR 601 & Single & 0.7 & 26 (119) & 5.0 & 49 (117) & 28 & $51(119)$ & 2.0 & $16(86)$ & 7.0 & $15(156)$ & 38 & $41(120)$ \\
\hline & & US & & $51(103)$ & & $56(78)$ & & $67(105)$ & & $55(49)$ & & 58 (103) & & $59(74)$ \\
\hline
\end{tabular}

${ }^{a}$ n.s.: non-significant readsorption $(<5 \%) .{ }^{b}$ n.d.: not detected, $<$ LOQ. RA: Readsorption (\%); RC: Recovery (\%). Recovery values are shown between parenthesis.

above fractions, diminished relative extractability as a result of increased readsorption is evident (e.g. Ni and $\mathrm{Zn}$ from BCR 601) in F3. However, the lower readsorption occurring for $\mathrm{Cr}$ and $\mathrm{Ni}$ when extracted from BCR 701 using ultrasonic agitation did not result in increased recovery, as could be expected. In both cases, low readsorption in the oxidisable fraction could compensate for low extraction efficiency thereby yielding similar recovery.

\section{CONCLUSIONS}

It is clear that readsorption occurs to some extent with the three approaches employed here for metal fractionation in soil and sediments. Readsorption is enhanced for many metals and fractions when ultrasonic agitation by a probe is applied to shorten the extraction time in comparison with the conventional SES, hence indicating the activation of adsortive sites. The readsorption artefact is particularly critical using the single extraction approach with BCR 141R soil, being enhanced by the presence of unattacked phases owing to reagent exhaustion.

For many metal/fraction pairs, recovery attained with the accelerated methods is related to readsorption. When readsorption for the accelerated methods is similar to that of the conventional SM\&T SES, recovery approaches $100 \%$. The readsorption phenomena suggest that metal distribution has to be cautiously interpreted, principally that of $\mathrm{Cu}$ and $\mathrm{Pb}$ due to severe readsorption focused on the acid soluble fraction. 


\section{ACKNOWLEDGEMENTS}

This work has been financially supported by Xunta de Galicia (Project PGIDIT05PXIB31401PR). The authors thank the CACTI Laboratory (University of Vigo) for assistance with the atomic emission spectrometer. Financial support from the Universitat Autònoma de Barcelona is also gratefully acknowledged.

\section{REFERENCES}

[1] Tessier, A.; Campbell, P.G.C.; Bisson, M. Anal. Chem., 1979, 51(7), 844.

[2] Ure, A.M.; Quevauviller, Ph.; Muntau, H.; Griepink, B. Intern. J. Environ. Anal. Chem., 1993, 51, 135.

[3] Filgueiras, A.V.; Lavilla, I.; Bendicho, C. J. Environ. Monit., 2002, 4, 823 .

[4] Tack, F.M.G.; Vossius, H.A.H.; Verloo, M.G. Intern. J. Environ. Anal. Chem., 1996, 63, 61.

[5] Ipolyi, I.; Brunori, C.; Cremisini, C.; Fodor, P.; Macaluso, L.; Morabito, R. J. Environ. Monit., 2002, 4, 541.

[6] Pérez Cid, B.; Lavilla, I.; Bendicho, C. Anal. Chim. Acta, 1998, $360,35$.

[7] Pérez Cid, B.; Lavilla, I.; Bendicho, C. Intern. J. Environ. Anal. Chem., 1999, 73, 79.

[8] Davidson, C.M.; Delevoye, G. J. Environ. Monit., 2001, 3, 398.

[9] Greenway, G.M.; Song, Q.J. J. Environ. Monit, 2002, 4, 950.

[10] Gulmini, M.; Ostacoli, F.; Zelano, V.; Torazzo, A. Analyst, 1994, 119, 2075.

[11] Ginepro, M.; Gulmini, M.; Ostacoli, G.; Zelano, V. Intern. J. Environ. Anal. Chem., 1996, 63, 147.

[12] Campos, E.; Barahona, E.; Lachica, M.; Mingorance, M.D. Anal. Chim. Acta, 1998, 369, 235.
[13] Pérez Cid, B.; Lavilla, I.; Bendicho, C. Anal. Chim. Acta, 1999, 378, 201.

[14] Gómez-Ariza, J.L.; Giráldez, I.; Sánchez-Rodas, D.; Morales, E. Anal. Chim. Acta, 1999, 399, 295.

[15] Kheboian, C.; Bauer, F. Anal. Chem., 1987, 59, 1417.

[16] Ajayi, S.O.; Vanloon, G.W. Sci. Total Environ., 1989, 87/88, 171.

[17] Whalley, C.; Grant, A. Anal. Chim. Acta,1994, 291, 287.

[18] Rendell, P.S.; Batley, G.E.; Cameron, A.J. Environ. Sci. Technol., 1980, 14, 314 .

[19] Sahuquillo, A.; López-Sánchez, J.F.; Rubio, R.; Rauret, G.; Thomas, R.P.; Davidson, C.M.; Ure, A.M. Anal Chim. Acta, 1999, 382, 317.

[20] European Comission BCR Information Reference Materials, Luxembourg, EUR, 1996. The certification of the total contents (mass fractions) of $\mathrm{Cd}, \mathrm{Co}, \mathrm{Cr}, \mathrm{Cu}, \mathrm{Hg}, \mathrm{Mn}, \mathrm{Ni}, \mathrm{Pb}$ and $\mathrm{Zn}$ and the aqua regia soluble contents (mass fractions) of $\mathrm{Cd}, \mathrm{Co}, \mathrm{Cr}, \mathrm{Cu}, \mathrm{Hg}, \mathrm{Mn}$, $\mathrm{Ni}, \mathrm{Pb}$ and $\mathrm{Zn}$ in a calcareous loam soil, CRM 141R.

[21] European Comission BCR Information Reference Materials, Luxembourg, EUR, 2001. The certification of the extractable contents (mass fractions) of $\mathrm{Cd}, \mathrm{Cr}, \mathrm{Cu}, \mathrm{Ni}, \mathrm{Pb}$ and $\mathrm{Zn}$ in freshwater sediment following a sequential extraction procedure BCR-701.

[22] European Comission BCR Information Reference Materials, Luxembourg, EUR, 1997. The certification of the EDTA-extractable contents (mass fractions) of $\mathrm{Cd}, \mathrm{Cr}, \mathrm{Ni}, \mathrm{Pb}$ and $\mathrm{Zn}$ in sediment following a three-step sequential extraction procedure CRM 601.

[23] Filgueiras, A.V.; Lavilla, I.; Bendicho, C. Anal. Bioanal. Chem., 2002, 374, 103.

[24] Pérez-Cid, B. Thesis, University of Vigo, 1998.

[25] Raksasataya, M.; Landon, A.G.; Kim, N.K. Anal. Chim. Acta, 1996, 332, 1 .

[26] Gilmore, E.A.; Evans, G.J.; Ho, M.D. Anal. Chim. Acta, 2001, 439, 139.

[27] Mossop, K.F.; Davidson, C.M. Anal. Chim. Acta, 2003, 478, 111. 